968

\section{SURVEY OF CONTINUOUS POSITIVE AIRWAY PRESSURE USE IN NEWBORNS IN IRELAND}

\author{
E.A. Kieran ${ }^{1}$, H. Walsh ${ }^{1}$, C.P. O'Donnell ${ }^{1,2,3}$
}

${ }^{1}$ Neonatology, National Maternity Hospital, Holles St, ${ }^{2}$. The Children's Research Centre; Our Lady's Children's Hospital, Crumlin, ${ }^{3}$ School of Medicine and Medical Science, University College Dublin, Dublin, Ireland

Aims: To assess the use of continuous positive airways pressure (CPAP) in Irish special and intensive care nurseries.

Methods: A one-page questionnaire on the use of CPAP was sent to a Consultant Neonatologist/ Paediatrician and a senior neonatal nurse at each of the 28 delivery units in the Republic and Northern Ireland. We asked for what clinical indications and in what patient groups CPAP was used; which pressure generating devices and nasal interfaces were used; and what pressures were used $\left(\mathrm{CmH}_{2} 0\right)$. We also asked about the use of NIMV/NIPPV/ BiPAP. Finally a question was asked about each units practice when discontinuing CPAP.

Results: Replies were received from doctors and nurses at all units $(56 / 56,100 \%)$. Nasal CPAP was used at 24/28 units. CPAP is used as an aid to extubation in all units who ventilate infants (24/24, $100 \%$ ). The Infant Flow Driver (Viays Healthcare, Yorba Linda CA, USA) is the most commonly used pressure-generating device used in 22/24 (92\%) units, SiPAP 14/24 (58\%) and Bubble CPAP in $5 / 24(21 \%)$. All units use short binasal prongs with over half of units also using nasal mask interfaces. Infants at 16/24 units receive NIMV, with a starting rate that varies (mean $25 \mathrm{bpm}$, range $10-50 \mathrm{bpm}$ ). All but 3 units give trial periods off CPAP before stopping treatment.

\begin{tabular}{|l|l|}
\hline Indication & No. Of units (\%) \\
\hline RDS in infants $\leq 26$ weeks & $9 / 24(38 \%)$ \\
\hline RDS in infants $\leq 28$ weeks & $17 / 24(71 \%)$ \\
\hline RDS in infants $\leq 32$ weeks & $24 / 24(100 \%)$ \\
\hline $\begin{array}{l}\text { Respiratory distress in } \\
\text { infants }>32 \text { weeks }\end{array}$ & $24 / 24(100 \%)$ \\
\hline Apnoea of prematurity & $24 / 24(100 \%)$ \\
\hline
\end{tabular}

[Results]
CONCLUSIONS: CPAP is widely used to support extremely preterm infants with RDS. When NIMV is used there appears to be a wide variation in the inflation rates and peak inflating pressures (PIP) that are used.

\section{9}

COULD EARLY NEONATAL FEATURES PREDICT THE NEED FOR USE OF A CERTAIN ANTICONVULSANT TO CONTROL NEONATAL SEIZURES?
A.I. Toma ${ }^{1}$, E. Matu ${ }^{1}$, D.F. Albu ${ }^{2}$, L. Nastase ${ }^{1}$
${ }^{1}$ Neonatology, ${ }^{2}$ Obstetrics and Fetal Medicine, Panait Sarbu Hospital, Bucharest, Romania

Backgroudn and aims: Using specific targeted anticonvulsivants in the postasphzxia seizures could result in an earlier control of these and less drug-associated toxicity. The aim of the study was to investigate if there are certain features in the case of newborns with postasphyxial seizures to predict that these will be controlled by only by Lidocaine.

Methods: In 15 neonates with postasphyxial seizures the treatment was as follows: Phenobarbital $20 \mathrm{mmg} / \mathrm{kg}$ i.v loading dose followed by another dose of $20 \mathrm{mg} / \mathrm{kg}$, followed by phenitoin $20 \mathrm{mg} / \mathrm{kg}$ loading dose and midazolam beginning with 0.06 $\mathrm{mg} / \mathrm{kg}$ to $1.2 \mathrm{mg} / \mathrm{kg} / \mathrm{hour}$. followed by Lidocaine 2 $\mathrm{mg} / \mathrm{kg}$ loading dose -10 minutes followed by $6 \mathrm{mg} /$ $\mathrm{kg} /$ hour for 12 hours, $4 \mathrm{mg} / \mathrm{kg} /$ hour for 12 hours and $2 \mathrm{mg} / \mathrm{kg} / \mathrm{hour}$ for 12 hours. There were noted: APGAR scores, $\mathrm{pH}$ and base excess in the umbilical artery at birth, time to first breath, aEEG pattern at 6 hours.

Results: There were significantly associated with the appearance of seizures that were controlled only by Lidocaine a Base Excess > - 20 (OR 2.11 [95\% Cl 1.37-3.32]), a time to first breath longer than 150 seconds (OR 1.92 [ 95\% Cl 0.37-2.92] and the appearance of a burst suppression (-) or low voltage background pattern at 6 hours OR 1.76 [95\% Cl 1.15-2.43].

Conclusions: Increased base excess in the umbilical artery, longer time to first breath and a depressed aEEG pattern could select from the population of neonates with postasphyxial seizures a cathegory in which the seizures could be controlled by lidocaine only. 